\title{
Decentralisation of Health Systems and the Fate of Community Health Fund in Tanzania: Critical Review of High and Low Performing Districts
}

\author{
Chakupewa Joseph Mpambije \\ Department of History, Political Science and Development Studies, Mkwawa University College of Education, Iringa, Tanzania
}

\section{Email address:}

chakjompa@yahoo.com

\section{To cite this article:}

Chakupewa Joseph Mpambije. Decentralisation of Health Systems and the Fate of Community Health Fund in Tanzania: Critical Review of High and Low Performing Districts. Science Journal of Public Health. Vol. 5, No. 2, 2017, pp. 136-144. doi: 10.11648/j.sjph.20170502.21

Received: January 18, 2017; Accepted: February 3, 2017; Published: February 24, 2017

\begin{abstract}
The deterioration of health services provision in Tanzania from 1980s to 1990s made decentralization of health service provision through the Health Sector Reform (HSR) a necessity. HSR aimed at bringing better utilization of scarce resources, improved quality of health services, increasing user access and cutting rising costs. It is through HSR that health insurance schemes were introduced. Community Health Fund (CHF) came as a result of such efforts. The efficiency and effectiveness of CHF rests on district councils which are responsible for ensuring better performance of CHF. Although the Government of Tanzania targeted $85 \%$ of the population to be members of CHF, enrollment has remained as low as $9.2 \%$ by 2014 . The most sticking problem is the variation in enrollment in different districts. There are districts with higher performance in CHF enrollment like Iramba (54\%) and Bariadi (40.9\%). Whereas, there are districts with very low enrollments in CHF like Liwale (8\%), and Rungwe (6.5\%). This paper is an effort to shed some light on this phenomenon ofperformance variation of CHF enrolment in districts. It argues that poor performing districts are constrained by their own weaknesses such as poor management and leadership capacities of Council Health Management Team (CHMT) and lack of motivation among health facility staff and allied health workers. Also, poor sensitization and mobilization of people to join $\mathrm{CHF}$, as well as poor quality healthcare to people has deterred performance of $\mathrm{CHF}$ in some districts. The papers' conclusion apart from offering recommendation also adds to the broader ongoing debate of decentralization process mainly through health insurance.
\end{abstract}

Keywords: Decentralization, Health Systems, Community Health Fund, Tanzania

\section{Introduction}

Community Health Fund (CHF) which was ushered under the decentralized system in Tanzania in 1996 was regarded as a prime solver of the health problems experienced during the 1980s and early 1990s. This system, which operates through prepaid system, was introduced targeting to enroll $85 \%$ of the citizens of Tanzania by the year 2015 [1]. However, low enrollment has been repeatedly identified as the persisted limitation to effective performance of $\mathrm{CHF}$ [2]. In fact, $\mathrm{CHF}$ has been found to attain penetration rates which rarely exceed $10 \%$, given the fact that by $2014 \mathrm{CHF}$ enrollment stood at $9.2 \%$ [3]. The most perplexing question, however, is the continued trend among districts where CHF operates to portray quite different levels of performance viewed mainly through enrolment rate ${ }^{1}$. Iramba, Bariadi and Singida, for instance, were the high performing districts having recorded the enrollment of $54 \%, 40.9 \%$ and $27.2 \%$ respectively by 2012 ; whereas Rungwe, Liwale and Ulanga were the poor performing districts recording $6.5 \%, 8.0 \%$ and $9 \%$ enrollment respectively. Such staggering variations among districts in $\mathrm{CHF}$ performance need to be analyzed given the fact that all the districts run $\mathrm{CHF}$ under the decentralized systems using the same policy guidelines from the Ministry of Health as well as

\footnotetext{
${ }^{1}$ Though CHF performance can be mirrored through different ways which this article will abide, but enrollment criteria is the surest way of rating high and low performing districts. Enrolment criteria is also used by the Government of Tanzania in rating high and poor performing districts
} 
President's Office Regional Administration and Local Government. To critically analyze this state of affair for CHF, this article, at the first outset, will situate the state of the centralization system and the provision of health service during the early days of independence, followed by tracing forces that prompted changes from centralized to decentralized system. Major changes that informed decentralization of the health systems will also be unraveled. Thereafter, promises and reality of CHF in strengthening health systems will be given due attention. Above all, reasons for the staggering differences of CHF performance under the decentralized system will be delineated with reference to poor performing districts and high performing districts. In so doing, secondary sources like policy documents, evaluation reports, training manuals, as well as hard and electronic journals will be employed while paying much attention to their authenticity, credibility and representation.

\section{Centralization and the Provision of Health Service in Tanzania: A synopsis}

The changing pattern of social service delivery in Tanzania, particularly healthcare has been happening in response to prevailed socio-economic change in the world which also determined the modality of providing such services to people. After independence in 1961, for instance, Tanzania provided social services through a centrally planned system known as the centralized system, which was done under the auspices of Arusha Declaration [4]. Under the centralized system, all production and distribution of economic and social services such as health and education were centrally managed. Centralized system is implemented in a circumstance where the costs of public spending are shared equally among districts [5]. In turn, this created expectations from both policy makers and the population that social services would be extensive and effectively reach the whole population [6]. Indeed, there were qualitative and quantitative benefits accrued from this system essentially from 1960s-1980s. For instance, the three christened enemies; disease, ignorance and poverty were reasonably been dealtwith [7]. Disease was fought through introduction in health systems a massive increase of health facilities, primary healthcare and of course, provision of free health services. Between 1972 and 1980s, the Government of Tanzania established a comprehensive health infrastructure such that in 1978 , approximately $72 \%$ of the population lived within five kilometers from a health facility and $90 \%$ within ten kilometer [8]. Access to primary health facilities and medical personnel improved rapidly, dispensaries and health centres increased from 1210 in 1961 to 2839 in 1980 [9]. The impressive investments and accomplishments of the 1970s could not be sustained through the 1980s as the government encountered difficulties in financing and managing the social services. By the end of the decade in 1980s, the system that had promised rapid improvement in human welfare failed to meet its ambitious coverage targets, and progress towards improved outcomes was lagging [10]. It was clear that the system would not live up to the challenges of the 1980s and 1990s. A policy alternative had to be sought to save the situation. This ushered in a move to the decentralized system, the reasons of which are given below.

\section{Change From Centralized to Decentralized System}

There exists a plethora of published works on economic and social plummeting of 1980s: see among others [10,11, 12, 13]. It is generally agreed that the economic crisis of 1980 s was real and that the centralized system could no longer perform any more miracles, hence the decentralized system had to take its course. Between 1976 and 1978 per capita GDP declined to average of $0.2 \%$ and between 1978 and 1984 an average GDP declined to -2.5 per annum. Inflation rate averaged $29 \%$ per annum: there was a drastic fall of commodity prices like coffee that fell by $36 \%$ and soaring of import price like oil that exorbitantly increased by $80 \%$ [11]. After a visit to Tanzania in 1982, a Norwegian radio commentator offered the following description over the economic and social worsening of Tanzania [14]:

On days when bread was delivered to the store, people had to line up for hours. Evencommodities, toothpaste, salt, flour, cooking oil, batteries and bandages were lacking. People starved, and the starving got desperate

The financial burden of the economic crisis is hard to estimate [12]. Nevertheless a conservative figure may be as high as $\$ 1.7$ billion according to 1978 prices comprising the loss of $\$ 630$ million due to imbalance terms of trade during 1973-1978; \$413 million as the cost of food (commercial and aid) imports; $\$ 500$ million as Uganda war cost and \$200 million due to the breakup of East African Community [12]. Such a situation resulted into the standing still of social service provision. [15], for instance, postulates that economic crisis brought unprecedented impact to the social service delivery including dilapidated public buildings, armies of urban unemployed, abandoned factories, potholed roads, and schools without teaching materials are all visible testimonies of Tanzania's deepening economic crisis. The health sector in particular faced severe underfunding that affected the quality and provision of healthcare service. According to Mohamed, health expenditure in Tanzania was reduced from 1.3\% GDP in $1986-1986$ to $0.6 \%$ in $1987-1990$ [16]. This resulted into collapses of healthcare systems; shortage of drugs, equipment, and medical supplies were felt high [7]. Again, total closure of clinics and hospitals was evidenced at this time which further resulted into poor management in health systems, very low wages and low staff morale $[7,17]$.

The intensification of poor provision of health services resulted in the need to revisit the efficacy of the centralized system to the new model. Under the auspices of International Monetary Fund (IMF) and World Bank (WB), the Government of Tanzania agreed to adopt decentralization process as a new 
system of running the state and rendering health service delivery in particular. From administrative perspective, decentralization is defined as the transfer of responsibility for planning, management and the raising and allocation of resources from the central government and its agencies to field units of government agencies, subordinate units or levels of government, semi-autonomous public authorities or corporation, area wide, regional or functional authorities, or non-governmental private or voluntary organization [18]. The need for decentralization of health in particular was motivated by the desire to bring politicians and policy makers closer to client and in long run to make health systems more equitable, inclusive and fair as well as making services to be more efficient and effective [19]. In Tanzania, the decentralization, apart from health sector, crossed over to other sectors like education and water. The health sector, however, was the most important sector which experienced major changes, hence the appellation 'Decentralisation of health systems" [20].

Major Changes that Informed Decentralization of Health Systems in Tanzania

The 1990s decentralization of health systems in Tanzania was done through Health Sector Reform (HSR) [21]. The reform aimed at bringing better utilization of scarce health resources, improving quality of health service, increasing user access, and cutting rising costs. Overall, the goals of the decentralization of health services under the HSR according to $[7,22]$ were among others:
- To improve health status and consumer satisfaction by increasing the effectiveness and quality of services;

- To obtain greater equity by improving the access of disadvantaged people to quality care;

- To obtain greater value for money (cost effectiveness from health spending, considering improvements both in the distribution of resources to priority activities) and the management and use of the resources that have been allocated (technical efficiency); and

- To improve the functioning and performance of the health system and consequently improve its quality and quantity of health service.

According to Zinnen and Stoamer, the HSR programme focused on decentralization by devolution of health services, financial reforms, including cost sharing, pre-payment and health insurance $[23,24]$. Under the cost sharing scheme, Tanzania introduced user fee in 1993. The fee was aimed at generating additional revenue that would bridge the gap in government allocation, improving availability and quality of health services, rationalizing utilization of healthcare services and improving equity and access to health services by pooling financial risks $[25,26]$. On the other hand, under health insurance, the prepayment was undertaken through introduction of National Health Insurance Fund (NHIF) and Community Health Fund (CHF), Social Health Insurance, Private Insurance Schemes and Micro-scheme as shown in Table (1) below.

Table 1. Forms of Health Insurance schemes in Tanzania.

\begin{tabular}{|c|c|c|c|}
\hline Insurance Scheme & Eligibility & Contribution rate & Benefit package \\
\hline $\begin{array}{l}\text { National Health Insurance } \\
\text { Fund (NHIF) }\end{array}$ & $\begin{array}{l}\text { Mandatory for public servants and covers up } \\
\text { to } 5 \text { dependants. Currently it isopened to } \\
\text { other members of the formal sector }\end{array}$ & $\begin{array}{l}6 \% \text { of gross salary, split between } \\
\text { employer and employee }\end{array}$ & $\begin{array}{l}\text { Inpatient\& outpatient care from public } \\
\text { and accredited faith-based and private } \\
\text { facilities and pharmacies }\end{array}$ \\
\hline $\begin{array}{l}\text { National Social Security Fund } \\
\text { (Social Health Insurance } \\
\text { Benefit-(SHIB) }\end{array}$ & $\begin{array}{l}\text { Mandatory for private and parastatal } \\
\text { employees and covers up to } 5 \text { dependants }\end{array}$ & $\begin{array}{l}\text { No earmarked contribution, } \\
\text { reimbursement funds taken from } \\
\text { NSSF contributions }\end{array}$ & $\begin{array}{l}\text { Outpatient and inpatient care up to Tsh } \\
80,000 \text { at selected facilities. Members } \\
\text { have to sign up in order to receive } \\
\text { benefits }\end{array}$ \\
\hline $\begin{array}{l}\text { Community Health Fund } \\
\text { (CHF) }\end{array}$ & $\begin{array}{l}\text { Rural-voluntary, household enrollment for a } \\
\text { couple and their children under } 18 \text { years }\end{array}$ & $\begin{array}{l}\text { Between Tsh 5,000-20,000 per } \\
\text { year/household }\end{array}$ & $\begin{array}{l}\text { Primary level public facilities. Limited } \\
\text { referral care in some districts }\end{array}$ \\
\hline $\begin{array}{l}\text { Private Insurance Schemes } \\
\text { (e.g. Strategies and AAR) }\end{array}$ & $\begin{array}{l}\text { Voluntary, often tied to employment- } \\
\text { individual cover }\end{array}$ & Various depending on benefits & $\begin{array}{l}\text { Various packages typically including } \\
\text { outpatient and inpatient care }\end{array}$ \\
\hline Micro Scheme (e.g. Chawana & Market vendors, individual enrollment & Ths 50/person/day & $\begin{array}{l}\text { Private outpatient care plus transport } \\
\text { to a referral facility and up to Tsh } \\
10,000 \text { referral costs }\end{array}$ \\
\hline
\end{tabular}

Source: Kawawenaruwa and Borgi (2012)

\section{Community Health Fund (CHF): Promises and Reality in Strengthening Health Service Provision in Tanzania}

After all indicators that the government of Tanzania could no longer manage to sustain financing ever increasing public health, the government opted for user fees. The user fees were intended to combat three aspects within the health sector: improving efficiency by moderating demand, containing cost, and mobilizing more funds for health care than existing services provided [27]. Though, there exists hot and inconclusive debate over sustaining or abolishing user fees, there is, in fact, a large body of evidence confirming that such health financing system on health has more substantial risks than its benefits $[28,29,30,31]$. It is argued, for instance, that user fees resulted from drastic and sustained decrease in health care service utilization and excluded the vulnerable population from access to health services and places them at risks of further impoverishment [30]. Faced with these problems, the solution to some African countries was to abolish such payments for everyone; while other countries like Tanzania introduced Community Health Fund (CHF). As Mushi succinctly notes, CHF was seen to be the best in financing 
healthcare as it shifts the incidence of the burden of financing away from the patients [32]. It is from this understanding that $\mathrm{CHF}$ needs to be discussed in a more detailed manner.

Community Health Fund (CHF) was introduced in Tanzania in 1996 as a government effort to make health care affordable and available to the rural population and those employed in non-formal sectors. CHF membership is voluntary and each household contributes an annual fee ranging from Tsh 5000 to 20000. The amount contributed entitles a particular household to a basic package of curative and preventive health services at health facilities and hospitals in some districts. The funds raised are doubled by a "matching grant" from the national budget (Health Basket Fund) subject to a particular district raising Tsh 5,000,000 or more in annual contribution [33, 34].

CHF is integrated at the district level through decentralized system in the following manner. At the national level, the Ministry of Health, as well as President's Office Regional Administration and Local Government render policy guideline and subsidies [24]. At the district level CHF is headed by the Council Health Service Board (CHSB) ${ }^{2}$ and Council Health Management Team (CHMT) ${ }^{3}$ led by District Medical Officer (DMO). Whereas at the Ward level there is Ward Development Committee (WDC) through Ward Health Committee, while at the village level there is a Village Council through the Health Committee and the Health Facility Governing Committee $(\text { HFGCs })^{4}[24]$. Nearly all districts have introduced the CHF, but few municipalities have introduced Tiba kwa Kadi (TIKA) $)^{5}$. Through the enshrined CHF Act of 2001, there are clear promises as highlighted by $[35,36,37]$.

- To establish a complimentary financial resources base for the basic curative and preventive health financing and provision;

- To ensure security of access and equity to healthcare services to the community members;

- To provide quality and affordable healthcare services through sustainable financial mechanism;

- To improve health care management in the communities through decentralisation; and

- To ensure equitable distribution of healthcare costs among different income groups and limit the rise in the cost of healthcare service.

${ }^{2}$ CHSB-Is a policy body consisting of elected and appointed members drawn from the public and the health sector in the districts. CHSB are responsible for ensuring delivery of appropriate, equitable and adequate health care services and overseers functioning of CHMT

${ }^{3}$ CHMT-is headed by District Medical Officer (DMO) who is advisor to District Executive Director (DED) on Health matters. Other staff on the core team include; Health Officer, Nursing Officer, Laboratory Technician, Pharmaceutical Officer, Dental Officer and Health Secretary. There can be other co-opted members who vary by council, (URT, 2007).

${ }^{4} \mathrm{HFGC}$-Are the overseers of the health centre and dispensaries and are drawn from the village and ward level. They are responsible for ensuring delivery of quality healthservices in their respective health facilities, thus they are taskedto develop the plans and budget of the facility, mobilize the community to contribute CHF and ensuring the availability of drugs and equipmentamong others

${ }^{5}$ TIKA-Is a similar scheme to CHF that was introduced in 2009 to operate in urban areas.
Apart from theoretical underpinning of $\mathrm{CHF}$, there are some practical achievements in some districts though not as it was desired. CHF has shown imporovements with regard to access to healthcare among peasants in rural areas which has also influenced health seeking behaviour among its members $[38,39]$. CHF has also managed to provide protection to their members by significantly reducing the level of out of pocket payment for healthcare. Such achivements of CHF, however, do not outweigh the fact that CHF has not attained its mission and vision for the two decades of its operation. According to [1] the government of Tanzania targeted enrollemnt to reach as far as $85 \%$ of enrolment from the day it was put into operation. Moreover, from 2010 to 2015, the Government of Tanzania commited itself to scale up CHF coverage to reach $45 \%$ by 2015 [40]. However, the enrolment rate has remained as low as $9.2 \%$ as of May, 2014 [3]. Such performance which is rated through the enrolled population is far below the target. Indeed, there is a problem.

While the national enrolmentstatus is much poorer compared to the national target, the story in the districts where decentralisation is put into practice reads differently. There are some districts that have recorded higher enrollement relatively above the national average mostly $10 \%$ and above, while others are still far below the national average. For instance, Bariadi District recorded $40.9 \%$ and Singida $27.2 \%$ from 2008-2010 [41]. Iramba District which has the highest record of enrollment nationwide recorded a54\% rate in 2013 [42]. Other high performing districts, with more than $10 \%$ of enrollment, include Hai District, Rombo District, Hanang District, Igunga District and Songea Municipal Council [43]. Districts with poor uptake in CHF in Tanzania include Liwale (8.0\%), and Rungwe (6.5\%) (Stoarmer, 2012). Other low performing districts with the enrollement below $10 \%$ are Ulanga, Kyela, Lindi and Mbinga, [43]. Such difference of high and low performing districts while they all work under decentralised system reveals that there are specific problems within each district that lead to failure of $\mathrm{CHF}$ to attain $85 \%$ of enrollemnt as targeted.

\section{Twenty Years of CHF Operation Under Decentralization System: Reasons for Existing Poor and High Performing Districts in Tanzania}

Although the operation and management of CHF changed from Ministry of Health and Social Welfare (MHSW) to NHIF in 2009, the role of the districts under the decentralized system to ensure that CHF runs successfully remains intact. The CHMT, CHSB and HFGCs at each district have had a commanding force for running CHF which makes decentralization of health system operate. It can, therefore, be argued that any meaningful success or failure of a particular district in CHF performance have to be looked from such structure. In view of the above, inthis paper, poor performing 
district and higher performing district will be discussed mainly based on how CHMT, CHSB and HFGCs execute their duties from the power vested in them by the CHF Act of 2001 as follows:

One problem hindering CHF is lack of CHMT, CHSB and HFGCs to take bold measures to sensitize and mobilize the masses to join CHF. Kamuzora and Marwa argue that poor sensitization leads to the failure of the community to understand the philosophy of the scheme which leads to impingement to the schemes expansion $[1,47]$. In a study by [41] it was revealed that the success of CHF in Iramba district was spearheaded by unique community participation and mobilization processes undertaken by CHMT, CHSB and HFGC. The study revealed that in Iramba District CHF is made a permanent agenda among the local government civil servants and it is hotly discussed in informal and formal meetings. In order to draw people closer to join CHF, Iramba District under the influence of the District Commissioner (DC) designed a slogan “Kuku mmoja CHF mwakammojakwakaya”literally "one chicken for CHF per year for household members [41]. The slogan convinced the community that one chicken can be sold at Tsh 10000 which can be used to join the whole household in CHF

Existing provision of poor quality health services among the health facilities is a cause behind poor performance of CHF in some districts. Jutting and White, emphasize that the delivery of high quality service is very important for mobilizing demand to enroll in Community Based Health Insurance (CBHI) [48, 49]. Some CHF members declare that they will not renew their membership if the quality of healthcare in the health centres does not improve [50]. Healthcare provision is said to be of low quality if there exists the following situation: shortage of drugs and essential medical supplies, inappropriate diagnosis due to lack of diagnostic equipment, particularly laboratory equipment; staff related problems; limited range of services provided and lack of possibility to use health facilities of members choice, coupled with referral problems [51]. In Igunga district, for instance, CHF attracted higher number of enrollment through improving quality health service provision. For instance, there was a deliberate addition of drugs and medical supplies to health facilities, rehabilitation of twenty health facilities, and establishment of referral system to Nkinga Hospital [52]. The success of Iramba to enroll 54\% of CHF members is largely due to embarking on quality delivery of health services. For instance, success in ensuring availability of drugs in all health facilities in Iramba resulted to the USAID/DELIER PROJECT and supply Chain Management System (SCMS) to name Iramba District a Centre of Excellence for Health Commodity Management since 2012 [53]. This is to argue that in districts with poor quality health provision will always suffer from poor enrolment rate contrary to those districts with appreciated quality service. This is in line with what [50] state "poor quality of the services provided does indeed appear as a crucial factor for non-enrolment and an important reason for non-renewal of membership in a $\mathrm{CBHI}$ scheme".
The role of CHSB and GHFCs in districts with poor performance in CHF is seen to be so low such that they do not consider themselves as part and parcel of the health systems in the district. In districts with higher CHF uptake the CHSB and GHFCs are highly empowered. According to [54] the CHSB and GHFCs are responsible for the following duties:to ensure delivery of appropriate and affordable healthcare services and mobilize and allocate resources using criteria that ensure equity, cost effectiveness and efficiency. Also, CHSB submits health plans and CCHP budget to the council for approval, analyze and approves CHMT progress reports, support CHMT in managing and administering health resources and promote community involvement through sensitization process. HFGCs on the other hand, have their duties including; receiving, discussing and approving plans, budgeting and progress reports at their levels while ensuring that the health services meet the required standards and satisfy the needs of the target population, identifying and soliciting financial resources for running the facilities and liaising with the CHSB and other committees and partners in health provision and promotion. GHFCs are charged with the responsibility of promoting health infrastructure, supplies and logistic system, advising the council on human resources development in terms of recruitment, training, deployment and motivation, and facilitating the management teams in planning and managing community based health initiatives within its catchment area.

Despite such roles that CHSB and GHFCs are vested with in poor performing districts they are not indeed serving the purpose. In a research done by [43] it was found that these boards are weak in most areas, which compromises their contributions for improving health services. Some CHMT members, particularly DMOs do not see the need for the boards and sometimes they question the relevance of being oversight bodies, while they are not "technical body" to oversee and approve the activities. The research found further that apart from limitation in education, CHSB and GHFCs face managerial incapacities. They include limited incentives to participate effectively at the community level in particular, limited financial means to carry out executive functions apart from meetings, the lack of annual action plans, as well as the lack of platforms for meetings and for sharing experiences. Districts with such problems of CHSB and GHFCs like Liwale have experienced low uptake of CHF [43].

In contrast, districts where CHSB and GHFCs have been given their due room to exercise their power managed to achieve quite impressive results in both raising the uptake of $\mathrm{CHF}$ and overall health provision. Kessy maintains that CHSB managed to facilitate fund raising for procuring equipment and improving infrastructure at the health facilities at Hai District Hospital and Kyela District Hospital [43]. It also sustained community sensitization and mobilization for $\mathrm{CHF}$ contribution at Liwumbu Dispensary in Songea Municipal Council. It further boosted morale and enhanced workers' responsiveness to the community and the public at the Igunga District Hospital and Kirokomu dispensary in Rombo District, 
and supervised construction and rehabilitation activities at the facilities. Also, CHSB and HFGCs reinforced the implementation of the exemption policy by making sure that pregnant women and children under five are exempted. From the above role by CHSB and GHFS, it can be said that in districts where these boards are effective, CHF uptake has gone higher.

Similarly, the failure of CHF depends largely on the capacity of CHMT to elicit highest commitment in planning; organizing and implementing $\mathrm{CHF}$ scheduled programmes. A large body of evidence shows that districts where CHMT exerted the highest commitment in supervising operations and practices of CHF have automatically resulted into higher enrollment. The study by [55] realized that low enrollment into CHF in Lindi district was largely caused by poor supervision by the CHMT. In Iramba, on the other hand, due to close supervision, CHF enrollment went higher. According to Maluka and Bukagile the CHMT in Iramba had established supervision and monitoring system which required all health facilities in the district to submit minutes of the meetings along with other reports to the CHMT on a monthly basis, from $1^{\text {st }}$ to $6^{\text {th }}$ date of every month [55] This system enabled CHMT to know challenges and successes of each health facility at the district level and attended them promptly. A study by [46] confirmed also the presence of committed CHMT members who effectively worked to see that CHF succeed. For instance, Kongwa, Kondoa and Dodoma urban districts' success has been attributed to improved cooperation between the CHMT, and other leaders who together mobilized the community to join CHF.

Empirical evidence confirms that financial and non-financial incentives for Health Facility Staff including $\mathrm{CHCB}$ and HFGCs are the main determinants of healthcare service quality, efficiency and equity [44]. This is equally true with CHF performance [45]. Districts that have effectively employed a number of incentive mechanisms have seen higher performance of CHF. For instance, CHSB and HFGCs whose duty in operationalizing CHF is voluntary in nature need to be highly motivated to exert and maintain an effort toward success of CHF. Kessy cemented convincingly that "assuming that HFGCs can just volunteer to do facility activities in the spirit of community participation is a wrong assumption" [46]. She concludes by asserting that financial incentive to the committee members to compensate for their time must be added similar to how it is practiced in other boards and committees in Tanzania. Highly performing districts in CHF have abided by this view as evidenced in Iramba District [55]. The CHMT in Iramba managed to ensure that HFGCs are paid incentives to compensate for their time for every meeting that is convened monthly to discuss success and failure of CHF in their health facilities. The chairperson and secretary of the committee were paid TSh 3,000, while other members were paid TSh 2,000 after every meeting [55]. In poor performing districts like Lindi, HFGCs were hardly paid or were paid very late sometimes even after three or four meetings (3-4 quarters). Consequently, some members of the committees did not attend the meetings as required.

Financial and non-financial incentives to health facility staff also influence CHF performance. Financial incentivesinclude salaries, pension, bonuses, allowances, loans [56] etc. On the other hand, non-financial incentives include promotion, training, education leave, housing, work environment, work time flexibility and work load, supportive supervision and recognition [57]. Others are support and respect, the effectiveness of feedback mechanisms, their participation in discussion of matters related to workers welfare and their perception of the adequacy and effectiveness of incentives. Districts that have employed decisive efforts to offer desirable financial and non-financial incentives have resulted in higher uptake of CHF. Iramba District, for instance, improved the living and working condition for the health facility staff. The Comprehensive Council Health Plans of 2012/2013 and $2013 / 2014$ revealed that out of 35 health facilities which had electricity, 28 facilities used solar power and 7 facilitieshad been connected to the National Grid. In the 2012/2013 financial year, the CHMT had planned to connect 6 more health facilities with solar power using CHF money [58]. In a study by Mpambije, it was proved that extra duty allowance was timely provided to the HFSs in Iramba each month based on their rank [42]. Clinical Officers received Tsh 50000, senior nurses Tsh 40000 and auxiliary nurses 30,000. Again, call allowance was timely given on monthly basis where clinical officers received Tsh 60,000 and nurses Tsh 30000. From all such efforts by Iramba District, for example, it is not surprising that enrollment in CHF reached a peak of $54 \%$ by 2013 which is the highest record countrywide.

Gross mismanagement of $\mathrm{CHF}$ funds is mentioned to have affected performance of $\mathrm{CHF}$ in several districts. There is a clear connection between the decentralized system and existence of mismanagement of funds at the district level. According to the National Audit Reports of 2010/2011, 2011/2012 and 2012/2013, some of Local Government Authorities (LGAs) failed to spend alarge amount of money that was directed to the improvement of $\mathrm{CHF}$ programmes as Table 2 below shows:

Table 2. Unspent money on Community Health Fund.

\begin{tabular}{|c|c|c|c|c|c|}
\hline Year & Amount allocated (Tshs) & Unspent amount (Tshs) & Percentage unspent & Number of LGAs involved & Average unspent balance per LGA (Tshs) \\
\hline $2012 / 2013$ & $4,118,548,131$ & $2,070,366,726$ & 50.3 & 81 & $45,007,972$ \\
\hline $2011 / 2012$ & $4,583,058,332$ & $1,709,747,559$ & 37.3 & 32 & $44,993,357$ \\
\hline $2010 / 2011$ & $5,463,660,702$ & $2,963,900,725$ & 54.2 & 33 & $89,815,173$ \\
\hline
\end{tabular}

Source: Auditor General reports 2010/11 to 2012/13 
It is revealed from Table (2) above that a total of Tsh $6,744,015,010$ (about $48 \%$ of the funds allocated) was not spent on implementation of CHF in the audited LGAs. CHF Act of 2001 stipulates usage of CHF funds on issues like purchasing of medicine, hospital equipment, minor building repair, paying water and electricity bills, paying allowance to watchmen, etc. Having unspent amounts of money implies that some of the services and procurements that could be done for CHF to function properly were not done [59]. This, in turn, debilitates possible performance of $\mathrm{CHF}$ in the already poor performing districts.

In course of mismanaging CHF funds, some LGAs spend $\mathrm{CHF}$ funds contrary to the stipulated guideline. Cash that is to be channeled to CHF so as to improve people's health are allocated to other areas. The National Audit Report of 2012/2013 identified seven Local Government Authorities that misallocated a total amount of Tsh 149,411,700 to other areas than CHF like Meru, Mbozi, Mwanga, Pangani, Bariadi, Lushoto and Mwanza [60]. Instead of spending the amount on health related purposes, the amount was used essentially on administrative expenses like payment of salaries, allowances, etc. A similar problem was also noted in the 2010/11 financial year where a total of Tshs44,086,650 CHF fund was spent on unrelated activities in Songea, Dodoma and Ulanga District Councils [61]. Incidences such as these, results into nothing else except eroding provision of proper quality of health services that, in turn, affects performance of CHF.

\section{Conclusion and Way Forward}

The socio-economic situation which prevailed in the 1980s in Tanzania provided a pressing need to revisit the modality of providing social services, particularly health services. Thus, decentralization of health services was unavoidable which resulted to the introduction of health insurance schemes such as CHF. The qualitative and quantitative benefit of CHF in districts with higher performance in CHF is noticeable. These districts commend positively the introduction of decentralized system. The problem is with poor performing districts in which decentralization of health service is perceived to be a burden. It is clearly established from this paper that most of causes for CHF failure in poor performing districts emanates largely from the districts' weaknesses. Issues like failure of CHMT and CHSB members to sensitize and mobilize the mass to join CHF, low empowerment of CHSB and HFGCs to execute their duties well and mismanagement of CHF funds have contributed to the underperformance of CHF. Other constrains for CHFfailure at the district level include little commitment of CHMT to supervise in planning, organizing and implementing $\mathrm{CHF}$ programmes and failure to provide financial and non-financial incentives to HFSs, CHSB and HFGCs.

It can be argued that poor performing districts in CHF have the capacity (if they wish) to surpass the today's higher performing districts. This will be made possible if these districts will come from their "closed doors" to see and learn from others. They will surprisingly realize that the secret behind their success lies within their power and capacity. This is in line with what the late Mwalimu Nyerere said in 1972 on the need to effectively mobilize human resources at the district level rather than waiting for those from the central government [62]:

When all power remains at the centre.... local problems can remain, and fester, whilelocal people who are aware of them are prevented from using their initiative in findingsolutions" This is to state that CHMT in collaboration with CHSB, HFGCs and the people at the grassroots can make CHF succeed by having a clear cut power relation among CHMT, CHSB and HFGCs and effectively cooperate together in achieving CHF laid down programmes. In this case, CHSB needs to have a very clearly documented annual action plan to be accomplished. CHMT also needs to execute power vested on them by the CHF 2001 Act. This will be done by introducing deliberate initiatives within the district of raising CHF enrollment. Pooling intellectual ingenuity of all CHMT members and other technical staff within the district to raise CHF uptake and performance is possible and indeed urgent. Motivating all those who earnestly work around the clock to see CHF uptake should be prioritized and adhered to especially by CHMT. Financial and non-financial incentives should mutually be applied. Above all, the CHMT who are overseers of health processes at the district level have the largest share of improving quality and quantity of health service provision. Their power needs to be seen and for sure this needs to be the first task in sustaining CHF under the decentralized systems. Consumers of health service who are potential prospective members of CHF are highly irritated by poor health services, such that they do not see any more reason of joining CHF. They need not to be irritated further.

\section{References}

[1] Kamuzora, P., \& Gilson., L. (2007). Factors Affecting the Implementation of the Community Health Fund in Tanzania. Health Policy and Planning 22 (2) 95-102.

[2] Macha, J, Kuwawenaruwa, A, Makawia, S, Mtei, G and Borghi, J (2014) Determinants of Community Health Fund Membership in Tanzania: A Mixed Methods Analysis. BMC Health Services Research 2014, 14: 538.

[3] URT. (2014). The Budget Speech Estimate for the Ministry of Health and Social Welfare (MoHSW) for the Financial Year 2014/2015. Ministry of Health and Social Welfare.

[4] Wobst, P. (2001). Structural Adjustment and Intersectional Shifts in Tanzania: A Computable General Equilibrium Analysis. Research Report 117 International Food Policy Research Institute.

[5] Besley, T., \& Coate, S. (2003). Centralized Versus Decentralized Provision of Local Public Goods: A Political Economy Approach. Journal of Public Economics 87: 2611-2637.

[6] Munga, A., Songstad, N. G., Blystad, A., \& Maestad, O. (2009). The Decentralisation-Centralisation Dilemma: Recruitment and Distribution of Health Workers in Remote Districts of Tanzania: BMC International Health and Human Rights 2009, 9:9 doi:10.1186/1472-698X-9-9. 
[7] Mujinja, P.G.M and Kida, T. M (2014) Implications of Health Sector Reforms in Tanzania: Policies, Indicators and Accessibility to Health Services. THDR 2014: Background Paper No 8 ESRF Discussion Paper 62.

[8] Kopoka, P. (2002). Health Service Delivery in Tanzania in the $21^{\mathrm{st}}$ Century. In Mbele, A et al (eds). The Nyerere Legacy and Economic Policy in Tanzania. Dar Es Salaam. Dar es Salaam University Press.

[9] World Bank and Ministry of Health (2003) A Country Status Report on Health and Poverty: Health, Nutrition, and Population inputs for the PRSP and HIPC process. The World Bank Africa Region Human Development\& Ministry of Health Tanzania January 2003.

[10] Wangwe, S. M., \& Rweyemamu, D. (2001). The State of Tanzania's Social Sector in the Development Context. Paper Presented Duringthe CSSC Stakeholders Consultation in Bagamoyo, Tanzania. November $2^{\text {nd }}, 2001$. Economic and Social Research Foundation (ESRF) Dar es Salaam.

[11] Ndulu, B. (1987). Stabilization and Adjustment Policies and Programmes: Country Study 17 Tanzania. New York: World Institute for Development Economic Research of United Nations University.

[12] Wagao, J. (1990). Adjustment Policies in Tanzania, 1981-1989: The Impacton Growth, Structure and human welfare. Innocent Occasional Paper. Number 9. International Children Development.

[13] Lipumba N. (1997). Theliberalization of foreign Exchange Markets and Economc Growth in Sub-Saharan Africa. World Institute for Development Economics Research, Helsinki, Finland.

[14] Rydenfelt, S. (1984). A Pattern for Failure: Socialist Economies in Crisis. Harcourt Brace Jovanovich $1^{\text {st }}$ Edition.

[15] Rugumamu, S. M. (2001). Africa's Debt Bondage: A case for Total Cancellation. EASSRR. Vol XVII No 1.

[16] Mohammed, N. A. L (1999). Social Dimensions of Structural Adjustment and Stabilization Programmes in OIC Member Countries.Journal of Economic 20, 2 (1999) 53-87.

[17] Isami, A. (2004). Impoverishing a Continent: The World Bank and the IMF in Africa. [online] Available www.halfaxinitiative.org/updir/Impoverishingacontinent.pdf $(5 / 12 / 2015)$.

[18] Rondinelli, D and Nellis, J. R (1986) Assessing Decentralization Policies in Developing Countries: The Case for Cautious Optimism. Developing Policy Review Volume 4, Issue 1Pg 2-23 DOI: 10.1111/j.1467-7679.1986.tb00494.x.

[19] Regmi, K. (2010). Understanding the effects of Decentralisation on Health Service. The Nepalise Experience. Journal of Health Organization and Management, Vol 24 No 4 pp361-38.

[20] Boex, J, Fuller, L and Malik, A (2015) Decentralized Local Health Services in Tanzania: Are Health Resources Reaching Primary Health Facilities, or Are They Gettinh Stuck at the District Level? Reserch Report: Urban Institute, International Development Report.

[21] Mills, A. (1998). Health Policy Reforms and their Impact on Practices of Tropical Medicines. British Medical Bulletin 54 (2) 503-513.
[22] Frumense, G, Nyamhanga, T, Mwangu, M and Hurt, A (2013) Challenges to the Implementation of Health Sector Decentralization in Tanzania: Expereince from Kongwa District Council. Global Health Action Volume 6 http://dx.doi.org/10.3402/gha.v6i0.20983.

[23] Zinnen, V. (2010). Sector-Wide Approach (SWA) as Support to Health Sector Reforms and Result at Operational Level in Rural Environment in Tanzania. University of Catholic de Louvain.

[24] Stoarmer, M. V, Radermacher, R and Vanderyden, M (2011) Transforming Community Health Funds in Tanzania into Viable Social Health Insurance Scheme: The Challenges Ahead. Schweizerisches Tropen-and Public Health (Swiss TPH).

[25] Mtei, G., \& Mulligan, J. (2007). Community Health Fund in Tanzania: A Literature Review. Consortium for Research and Equitable Health Systems (CHEHS) London School of Hygiene and Tropical Medicine.

[26] Kawawenaruwa, A., \& Borghi, J. (2012). Health Insurance coveris increasing among the Tanzanian population but wealthier groups are more benefiting. Ifakara Health Institute. Spotlight Issue 11.

[27] Karungi, G., \& Klazinga, N. (2005). Exploring the Relationship Between Privatisation of Health Care and Infant Mortality in Africa. Health Policy and Development Journal, Vol, 3, No 2, pp 144-153.

[28] Kwesiga, B. (2015). Whopays and Who benefits from Health Care Services in Uganda? BMC Health Services Research 15:44 DOI: 10.1186/512913-015-0683-9.

[29] O'Donnel, W. (2007). Access to HealthCare in Developing Countries: Breaking Down Demand side Barriers. CadSaude Publica, Rio de Jeneiro 23 (12) 2820-2834.

[30] Morestin, F., \& Ridde, V. (2009). Theabolition of user fees for Health services in Africa Lessons from the Literature. Université de Montréal.

[31] Laterveer, L Munga, M and Schwerzel, P. (2004). Equity Implications of Health Sector User Fees in Tanzania: Do we Retain theUser Fee or Do we Set User F(r)ee? Research On Poverty Alleveiation (REPOA).

[32] Mushi, D. P. (2015). Financing Public HealthCare. Insurance, Use Fees, or Taxes? International Journal of Current Research in Biosciences and Plant Biology. Volume 2 No 1 pp 16-29.

[33] Haazen, D. (2012). Making Health Financing Workforthe Poor People in Tanzania. Washington D.C. The World Bank.

[34] Borghi, J. M., Makawia, S \& Kuwawenaruwa, A. (2014). The administrative Costs of Community Based Health Insurance: A case of the Community Health Fund in Tanzania. Health Policy and Planning, 1-9.

[35] Kiwara, A and Kapinga, A. (2001). Quantitative Evaluation of the Community Health Fund in Igunga. Report submitted to the Ministry of Health and Social Welfare United Republic of Tanzania.

[36] Munishi, G. (2001). Constraints to Scaling Up Health Interventions: Country Case Study: Tanzania, CMH Working Paper Series No. WG5:16.

[37] Shaw, R. P. (2002). Tanzania's Community Health Fund: Prepayment as an Alternative to User Fees. 
[38] Basaza, P. G., Pariyo,G., \& Criel, B. (2009). What are the Emerging Features of Community Health Insurance Schemes in East Africa?Risk Management and Health care Policy Dove Press Journal.

[39] Msuya, J. M., Jutting, P. J., \& Asfaw, A. (2004). Impacts of Community Health Insurance Schemeson Health Care Provision in Rural Tanzania.ZEF.

[40] Humba, E. (2011). Pioneering social health insurance in Tanzania: The case of the national health insurance fund. Paper presented at the meeting.

[41] Stoarmer, M., Hanlon, P.,Tawa, M., Macha, J., \& Mosha, D. (2012). Community Health Fund in Tanzania: Innovation Study. Report submittedto GIZ.

[42] Mpambije. C. J. (2014). Management and Leadership Practices and the Performance of Community HealthFund in Tanzania: A Comparative Study of Iramba and Iringa Districts. Un-published MA Dissertation, University of Dar es Salaam.

[43] Kessy, F. L. (2014). Improving Health Service Through Community Participation in Health Governance Structure in Tanzania. Journal of Rural and Community Development, 9(2), $14-3$

[44] Paul, F. (2009). Health Workers Motivation and the role of performance BasedfinanceSystems in Africa: A QualitativeStudy of Health Worker Motivation and the Rwandan Performance BasedFinanceInitiative in District Hospital. Working Paper Series No 08-96 London School of Economics and Political Science.

[45] Tabor, S. R. (2005). Community- Based Health Insurance and Social Protection Policy. Social Protection Discussion Paper Series No 0503. Social ProtectionUnit, Human Development Network, the World Bank.

[46] Kessy, F. (2008). Technical Review of Council Health Service Boards and Health Facility Governing Committees in Tanzania: Reportprepared for the Ministry of Health and Social Welfare, Dar Es Salaam, Tanzania.

[47] Marwa, B., Njau, B., Kessy., \& and Mushi, D. (2013). Feasibility of Introducing Compulsory Community Health Fund in Low Resource Countries. Views from the Community in Liwale District of Tanzania. BMC Health Service Resarch 13;298 DOI:10.1086/1472-13-298.

[48] Jutting, J. (2004). Community Based Health Schemes Improved Poor People's Access to Health Care? Evidencefrom Rural Senegal. World Development. 32(2)288-378.

[49] White, J., Hanlon, B., Chee, G., Malangalila, E., Kimambo, A., Coarasa, J., Callahan, S., Lerey, I.R., \& McKeon, K. (2013). Private Health Sector Assessment in Tanzania: Washington. The World Bank.

[50] Platteau, J.P and Ontivero, D.U. (2013).Understanding and Information Failures in Insurance: Evidence from India. University of Namur, Centre for Researcher in Economic Development and University of Oxford.
[51] Defourny, J., \& Failon, J. (2008). Community Based Health Insurance Scheme in Sub Saharan Africa: Which Really Influence Enrollment? Working Paper. Centre for Social Economy. [Online] available http://orbi.ulg.ac.be/bitstream/2268/11566/1/CBHI\%20Defourny -Failon\%202008.pdf. (March 15, 2015).

[52] Faty, P. Mwanga, J., \& Shimoda, M. (2012). Best Practice Handbook: Tanzania Osaki Alumni. Dodoma. Prime Ministers' Office Regional Administration and Local Government.

[53] USAID. (2012). Tanzania: Iramba Health Supply Chains Goes From Failing to Model System Project, Task 4 and SCMS. Available scms.pfscm.org/scms/docs/papers/DELIVER_ToolsNewsAugust 2013.pdf accessedon 10/03/2015.

[54] United Republic of Tanzania (2001). Community Health Fund Act. Dar-es-Salaam: Government Printer.

[55] Maluka, S \& Bukagile, G. (2013). Implementation of Community Health Fund in Tanzania: Why do Some Districts perform Better than others? The International Journal of Health Planning and Management. Doi:10.1002/hpm.2226.

[56] Mathauer, I., \& Imhoff, I. (2006). Health Worker Motivation in Africa: The Role of non-financialIncentives and Human Resource Managementtools. Human Resources for Health, 4:24. [Online] available http://www.human-resourceshealth.com/content/4/1/24 accessedon 27/02/2015.(February 27, 2015).

[57] Munga, M., \& Mbilinyi, D. (2008). Non-financial Incentives and the Retention of Health Workers in Tanzania: Combined Evidence from Literaturereview and Focused Crosssection Study. EQUINET Discussion Paper Series NIMRI, EASA-HC, EQINENT.

[58] Iramba District Council. (2013). Comprehensive Council Health Plan 2013-2014 Iramba. Iramba District Council.

[59] Poncian, J., \& Mpambije, C.J. (2015). The Fallacy of Limited Financial Resources for Development in Tanzania: Evidence from Local Government Authorities Audit Reports. Paper accepted for Publication in the journal of Public Policy and Administration Research. Volume 5(2).

[60] NAO. (2014). Annual General Report of the Controller and Auditor General on the Financial Statements of the Local Government Authorities for the Financial Year Ended 30th June, 2013. [Online] available:http://nao.go.tz/?wpfb_dl=82.(March $10,2015)$

[61] NAO. (2012). Annual General Report of the Controller and Auditor General on the Financial Statements of the Local Government Authoritie for the Financial Year Ended 30th June, 2011. [Online] Available: http://nao.go.tz/?wpfb dl=78. (Retrieved March 10, 2015).

[62] Maro, P. S., \& Mlay, W.I.F (1977). Decentralization and Spatial Equity in Tanzania: A Proposal for Assessing Achievements. East African Geographical Review No 15. PP 33-42. 